\title{
DOI: 10.7596/taksad.v5i4.611
}

\section{Sustainable Urban Regeneration with a Physical Infill Development Approach: a Case Study on Isfahan Central Region}

\author{
Farzad Momeni*1, Mehrdad Keyhanfar ${ }^{2}$
}

\begin{abstract}
The idea of regeneration and revitalization of historical distressed urban areas has been the focus of academic and scientific discussions over the last five decades. The evolution of these ideas, from a mere physical approach after the reconstruction of World War II ruins to the ideas of urban sustainability, has always been in line with adjustments to circumstances and accelerated developments in cities. The present study aims to investigate one of the new approaches to renewal, improvement and modernization of distressed urban areas to examine sustainable urban regeneration approach based on physical approaches. Multiple topics were examined in the case study conducted in Isfahan districts 1 and 3 to propose restructuring strategies for these historic districts using analytical methods. We employed analytical methods such as ArcGis software for reaching conclusions and obtaining results. The findings from the case study suggested a structural gap between the northwest district and Isfahan districts 1 and 3 restructuring strategies. Also, the strategies and suggestions regarding the discussion points are extracted.
\end{abstract}

Keywords: Sustainable Urban Regeneration, Physical Approaches to Urban Regeneration, Restructuring, ArcGis.

\footnotetext{
$1 *$ Corresponding Author, Master of Urban Design. E-mail: momeni.phd21@yahoo.com

${ }^{2}$ Master of Urban Planning.
} 


\section{Introduction}

Drawing on Iran Urban development review of literature over the last four decades, historic urban textures have been among the most important municipalities activities and other urban development related institutions and entities. Additionally, numerous laws, bylaws and regulations are passed (Kamrava, 1389). Without a doubt, the problem of historic urban textures is one of the most important issues facing the community of specialized and urban development experts. This is while based on the concepts, instances and features; intervention approaches to these textures are seriously and ambiguously challenged. On the one hand, paying less attention to special organization of textures in historical urban development programs, represents lack of knowledge and awareness about the Cultural and economic values of historic textures, restructuring and changing historic areas proportional to the supply of utilities, etc. all of which are threatening and destructive factors that turn historic textures into massive ruins and cheap neighborhoods in the center of the cities. On the other hand, hasty measures taken in urban management towards expanding urban growth boundary and inattention to inner city development potential has led to the current underdevelopment of historic urban textures. The current study investigated sustainable urban regeneration strategies based on inner physical development measures to outline an internal approach to urban development issues that can highlight the importance of inner development and inner potentials of historic textures. To that end, districts 1 and 3 historic textures were examined as sample cases of the study. The fundamental question the study seeks to find an appropriate answer to is "what are the characteristics and features of Iran historic textures based on which renovation and improvement strategies can be directed towards urban inner development strategies?" Having said that, the physical aspects of sustainable urban regeneration strategies, executive policies and their indices were explored and ultimately the optimum renovation and improvement strategies are proposed.

\section{Research Methodology}

A descriptive-analytic method was employed in the present research using library documents and field studies. The quantitative results of the study were spatially displayed using Gis and ArcGis softwares. 


\section{Review of Literature}

It has been over three decades the urban development and restoration have created a theoretical atmosphere for the experts of the field. The term "regeneration" entails a very extensive semantic scope and introduces a new horizon for old and historic texture (Falamaki, 1386: 84). In the 1980s, the regeneration policies appeared in Western countries. England can be taken as a pioneer in sustainable urban policies. In this country, the government tried to revitalize distressed textures by establishing urban civil development companies, expanding support for private sector through tax regulations, defining special districts and encouraging investors through privileges. This renovation movement with a mere physical orientation (Kalantari, Khalil Abad, pour Ahmad, 1385: 75) and paying attention to economic efficiency (Sahizadeh and Izadi, 1383: 17-19) was gradually criticized by local and state governments and resulted in changing their measurements towards the policies and in the 1990s, a new city policy was formed as a challenge. According to these policies, local governments were asked to propose ideas to central government about carrying out projects in their district in partnership with private sector, public sector and collaboration volunteers. These projects were conducted in areas where people were suffering from poor quality of urban life and environment instead of in distressed textures. Therefore, the central government tried to propose a special model regarding urban issues through coordination policies of longitudinal urban interventions and expansion of processes on latitudinal scale (Kalantari, Khalil Abad, pour Ahmad, 1385: 75).

The main focus of interest to the policies were as follows:

a. Continuity of emphasis on partnership of local forces with private sector and volunteer groups.

b. Returning attention to social status of cities and society-oriented issues of 1960s and early 70s; emphasizing social groups participation in the processes, deprived groups participation in economics processes through providing techno-vocational trainings to them.

In the meantime, and along with new theories of environment-oriented planning, (Daneshpur, 1382), new approaches towards creating sustainable environment are also effective indices of the observed process of changes (Sahizadeh and Izadi, 1383: 17-19). This has directed regeneration towards sustainability and has created the concept of sustainable regeneration policy (Rogres, 1999). In fact, sustainable urban regeneration is obtained through improving 
cities social, economic and environmental life and describes a wide range of activities that bring a new life to distressed textures and revitalize buildings, infrastructures, environment and urban facilities (Galdini, 2005). In this regard, the oldest term used for sustainable urban regeneration, encompasses a combination of deep studies of previous works, physical and none-physical measures in urban texture and other shareholders' applications. Additionally, sustainable urban regeneration has gone from simple restoration and rehabilitation of infrastructures, deteriorated facilities and built lands to restructuring urban texture, renewal of economics and landscapes with the purpose of more social interactions, rights equality, locals' participation, and professional and social integrity in a multi-functional field (Hanachi et.al, 1386). Today, sustainable urban regeneration is an integrated part of urban policies at the national level. It has turned into a new activity since urban realms are the necessary ground for their implementation and strategies testing. This is because, this approach is carrying out sustainable development principles which theoretically implies the low dispersion of cities, fighting against pollution, general health, preventing genetic and environmental disorders that point to understanding of urban complexities. In retrospect, sustainable urban regeneration is moving towards creating a new identity that fits into today's living conditions without ignoring identities of different periods. This approach to regeneration of urban textures as opposed to globalization, structural changes and lack of spatial balance originates from massive city growth (Hajipour, 1385: 17). In this approach, the past is a starting point towards the future and targets human-space dialectic, without being involved in historical sorrow. This way, the passage of time remains in a spatial bond as a stash for memories of the seconds the city has gone through and is seen as a unique opponent for degradation caused by aging and performance (Habibi, Maghsudi, 1386: 2).

\subsection{Sustainable Urban Regeneration Policies}

Reconstruction and renovation of distressed areas entails complicated responsibilities with complex aspects. In this process, if one or more aspects are not considered all the efforts may become useless or have negative effects. Thus, various aspects of development should be considered in policy-making processes. With this explanation, sustainable urban regeneration policies can be classified based on multiple aspects of the policies effects on decisionmakings which itself can be classified in the form of physical regeneration policies, social regeneration policies, economic regeneration policies, organizational arrangements policies and spatial scale. 


\subsection{Physical Regeneration Policies}

With regards to the study questions and a brief look at the purpose of the current study, which is analyzing the strategies used for historic areas urban regeneration of Isfahan districts 1 and 3 , physical regeneration policies are studied as one aspect of sustainable urban regeneration multiple aspects. Physical regeneration policies of land revitalization and infill developments are investigated as follows. They are obvious aspects of poverty and economic decline. Also they are signs of urban inability in sufficient adjustment to quick economic and social changes that impose costs for restoration which is beyond economic capacities. They are limitations that bring physical and environmental destruction to cities. On the other hand, there is potential in the cities to which paying attention creates opportunities for urban development. Physical regeneration along with physical elements analysis address limitations and physical potentials that adjust city physical appearance to quick social and economic changes (Porats, 2004). Therefore, the main purpose of physical regeneration policies is making distressed areas attractive to people with a variety of choices. Physical quality improvement, size and type of housing variety, inclosing brown fields, providing retail facilities, shopping and entertainment, transferring incompatible land uses are among the most important physical regeneration policies.

\subsubsection{Recycling, Revitalization and Land Assembly Approach}

Recycling, revitalization and land assembly approach is a commonly used approach in physical revitalization practices and is applied to abandoned and dirt lands and buildings. Recycling is used for buildings and all the three are used for lands depending on the circumstances each of which are studied separately as follows (Rogres, 1999: 78).

\subsubsection{Buildings Recycle:}

Recycling for buildings helps maintain or boost land uses of a building and is applied to three types of buildings:

a. Abandoned buildings: such buildings do not have a particular usage and are in good physical condition.

b. Buildings with low activity: Buildings with no optimum use are in this category. Optimizing such buildings through injecting new roles to them leads to building recycle. 
c. Historical buildings: Such buildings create a good opportunity for the study area. Recycling them improves the economic status of the study area.

\subsubsection{Recycling, Revitalization and Land Assembly:}

These are applied to urban lands depending on the circumstances and conditions as follows:

a. Abandoned lands that have been damaged by various developments and require revitalization which include lands with no land use, excavations and dirty lands.

b. Empty lands with no developments and can be developed through recycling.

c. Lands comprising of different small areas and thus in inappropriate conditions. Land assembly creates necessary condition for their development.

\subsubsection{Infill Development Approach}

Infill development approach is a development based on urban capacity use. In this type of physical development, the purpose is to maintain ground ecology and interior borders. This approach to urban physical development is raised in response to expanding urban horizons (The Syndicate of Consulting Architects and Planners, 1387). The purpose and indices of infill development are as following:

- Maintaining open areas, farms and orchards through reducing pressure in green areas

- Creating opportunities for revitalization of neighborhoods or downtowns

- Increasing tax basis in specific areas through creating land values or values revitalization

- Allocating proper and efficient land use to abandoned lands or brownfields

- Sustainability improvement through proper use of infrastructures and social facilities

- Supporting dense development and increasing urban density

- Combining land uses

Therefore, key indices of infill development can be classified as the following: functional zoning principles, physical infrastructures, general services structure, financing, ownership etc. from which land and building use development, services structure and ecologic maintenance are the most important (Porats, 2004: 148). 


\section{Theoretical Framework of the Study}

The theoretical framework of in the form of a theoretical model should be primarily set according to prior investigations in order to define the right path to identify sustainable regeneration approaches based on physical policies. In accordance with case studies results, urban regeneration physical approach is based on the three principles of service structure, land-building and ecological maintenance areas.

Each of these principles directly affects urban regeneration policy making process, but an integrated approach regarding these effects is required. Consequently, the integrated model of urban physical regeneration encompassing the three principles is presented in the following diagram:

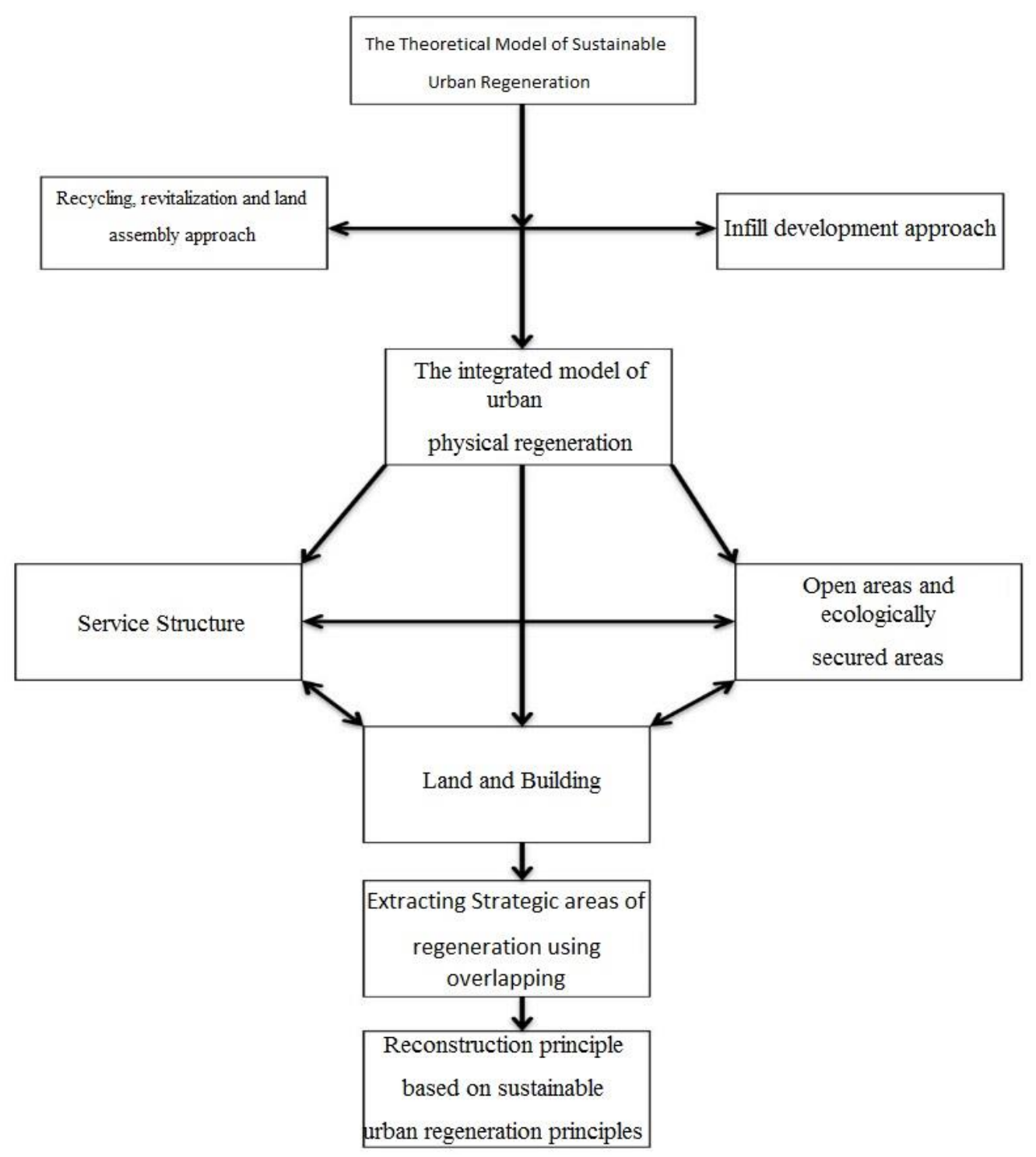

Figure 1. Building quality 
The above mentioned overlap in the theoretical model has been extracted through quantitative indices and studying each of the three principles as information layers combined in Arc Gis Software. Finally, the expected data was extracted.

\section{Case Study}

\subsection{The Study Area Introduction}

The study area of the current study area is Isfahan $1 \& 3$ districts. These areas are located in the historic texture of Isfahan, which contain historical values at different historical periods, so this area is constantly exposed to a variety of policies as well as restoration and improvement programs of Isfahan historic texture. Considering the past policies in this historic area, it is obvious that addressing improvement in this area requires a shift from traditional restoration approaches to sustainable urban ones. Therefore, attending to the historic value of this region needs an integrated regeneration model with physical approach.

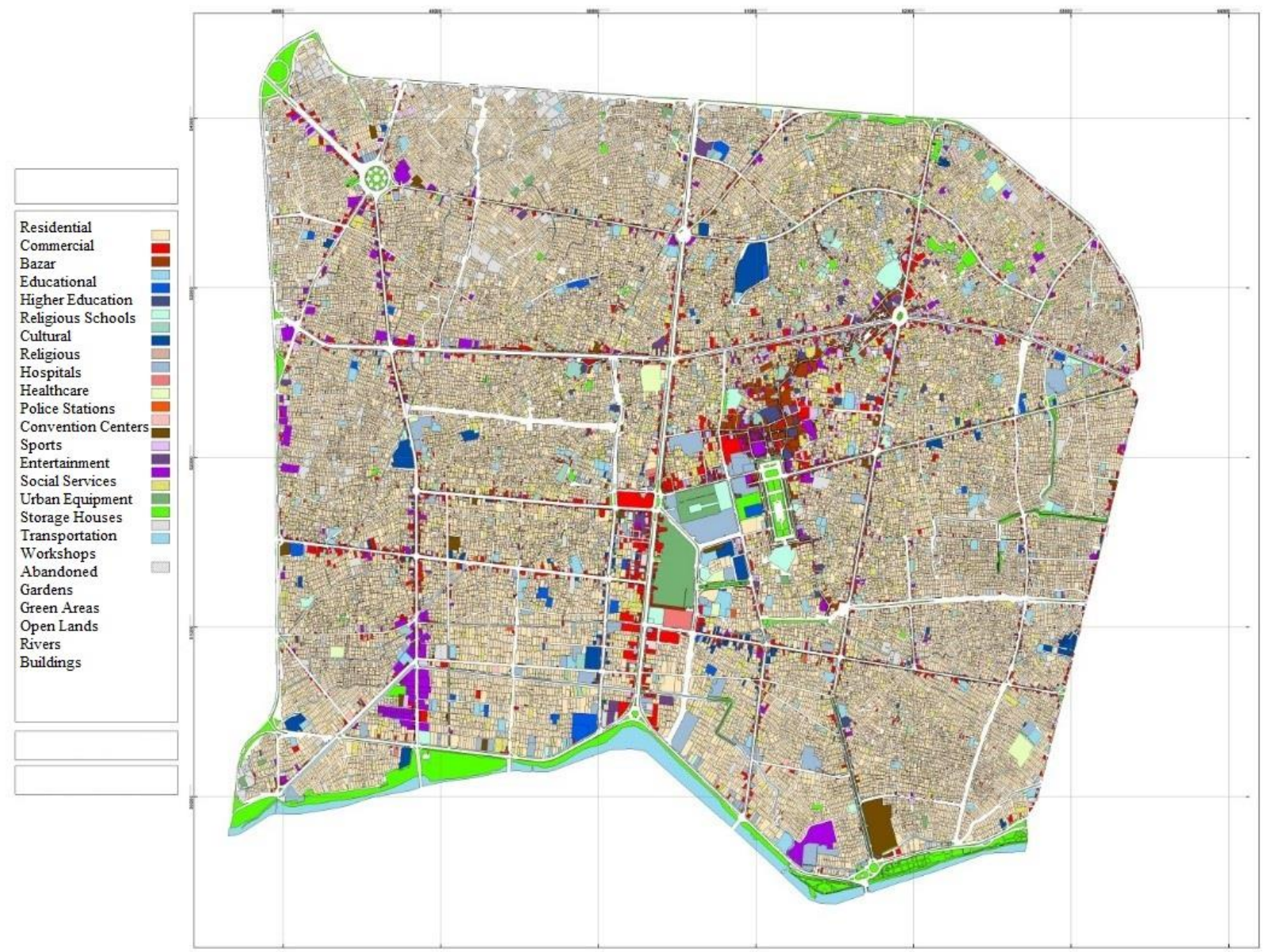

Figure 2. Study map, districts $1 \& 3$ 


\subsection{Methodology and Findings}

As mentioned before, the theoretical framework of the study includes an integrated model of three policies of sustainable physical regeneration. Each of these policies and principles has its own indices. First, the potential areas are determined based on the above-mentioned specifications. Then, the areas with priority for physical regeneration are determined based on the overlapping areas of layers. Indices of each principle is as following:

- $\quad$ Land \& building

- Deteriorated buildings, destroyed buildings, abandoned building, brownfields, etc.

- Open areas and ecologically secured areas, orchards, green areas, open areas with no particular land use.

- Service structure, including all service structures in the study area

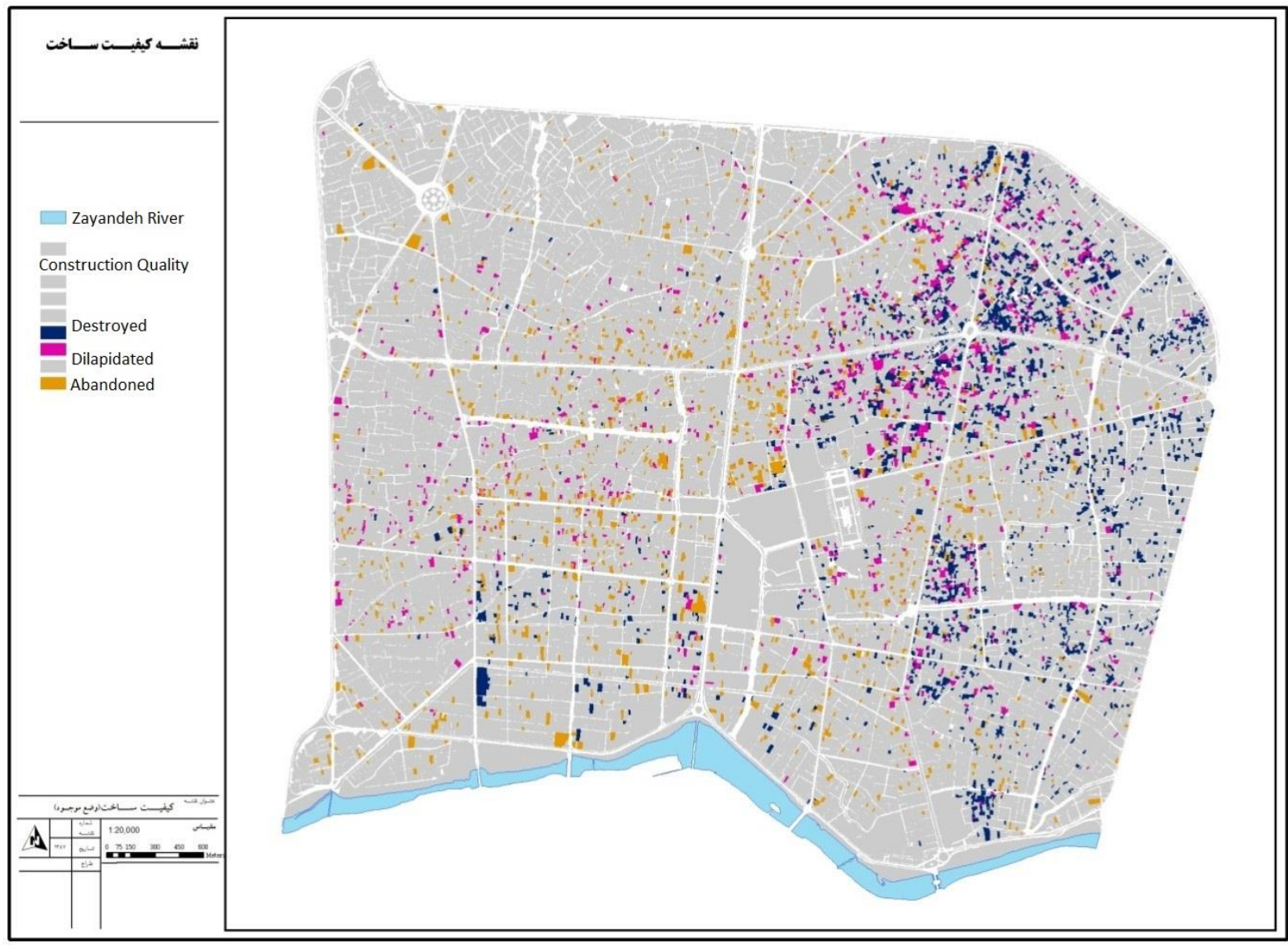

Figure 3. Building quality map 
As presented in Figure 3, the distribution of deteriorated, destroyed and abandoned buildings, that are considered as potentials of infill development, is more in the old centers of Isfahan which itself creates an opportunity for physical adjustment of this are to urban changes. This upgrade is incorporated into urban regeneration strategies.

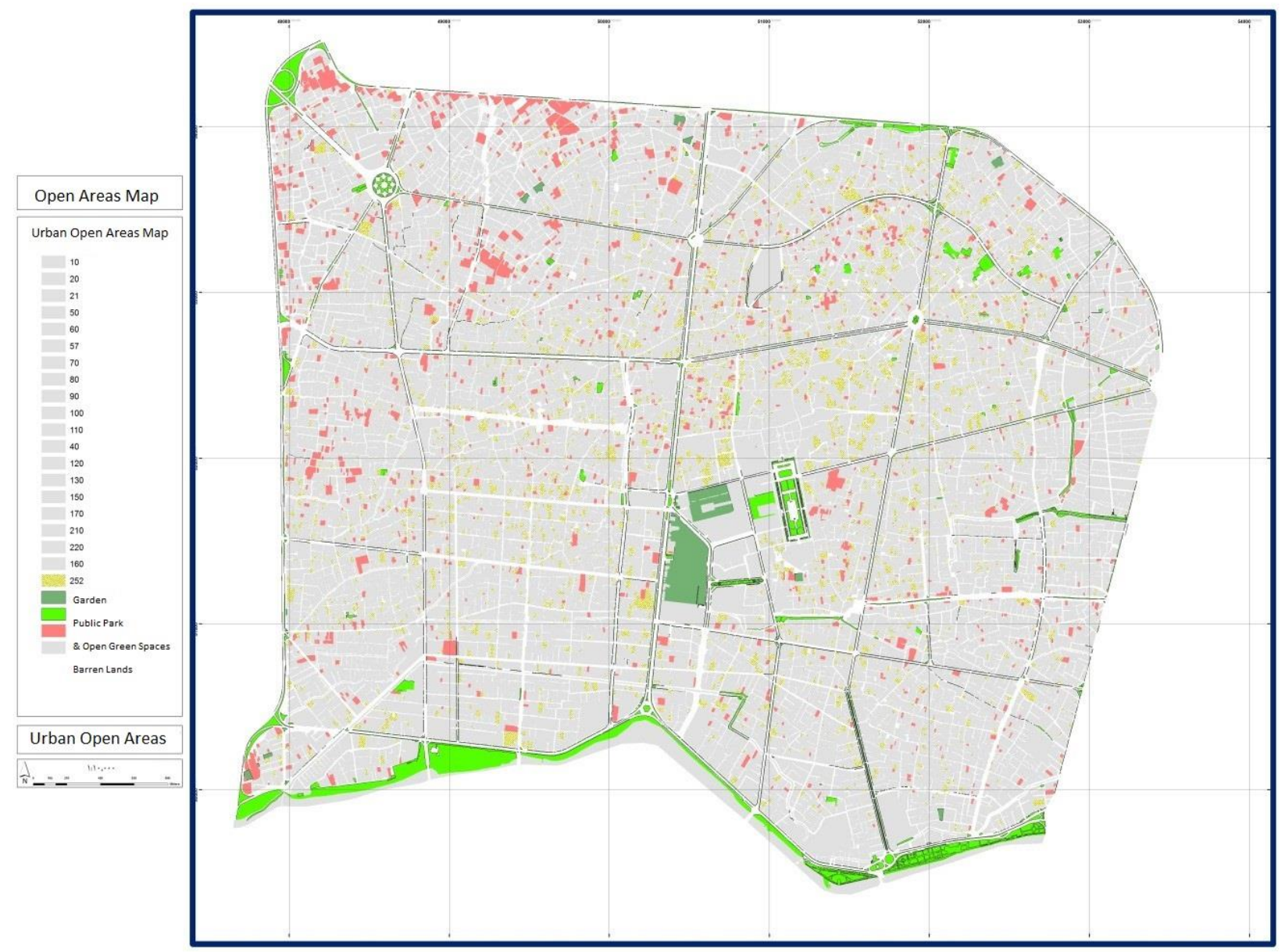

Figure 4. Open lands and ecological areas

Figure (4) represents the open lands and natural areas of the study. The observed distribution type indicates a large area of brownfields in the northwestern part, ending in Jomhouri and Shohada Squares which are potentially good for the study area. These areas without land use are considered as important districts for new constructions. 


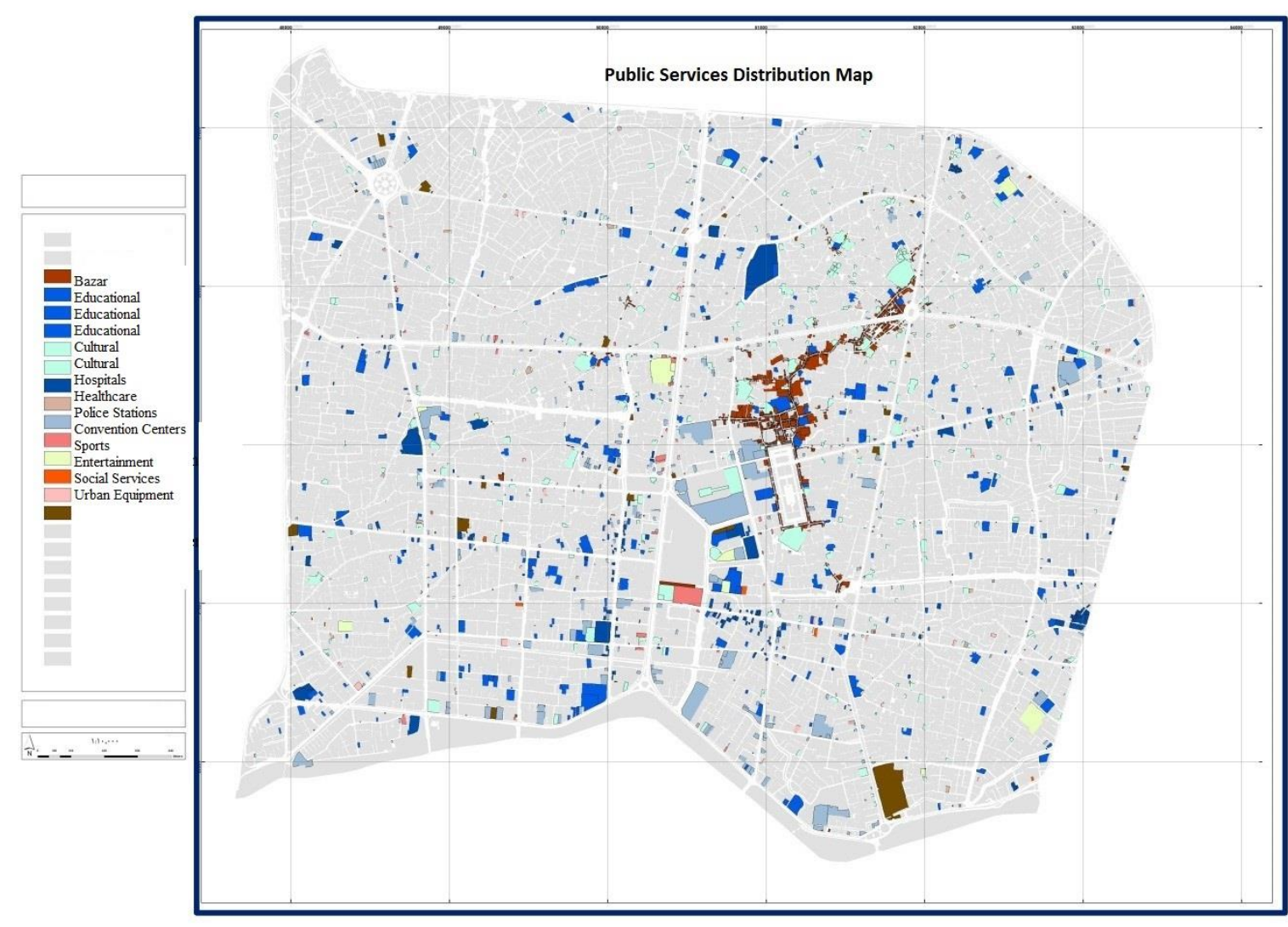

Figure 5. Service structure distribution map

Figure 5 displays service structure distribution of the study area. The main service areas focus is in the central part of the old and historic city parts. In other parts and areas depending on the type of urban operation and use, services structure has a rather uneven distribution. After extracting the basic layers of the model indices, in this part of the paper the overlapping layers of the areas are examined. The purpose of this is to extract strategic areas that play a role in the proposed structure of the area. These areas entail the following conditions:

- Each of these areas have a wide range of potential for new construction based on the ground capacity, structure quality and land use respectively.

- Each of these areas are related to ecological and urban open spaces. This relationship plays an important role in the proposed structure of the areas.

- Each of these areas are related to urban public service structure of the study area. Public service structure is the most important reconstruction principle based on sustainable urban regeneration principles. 


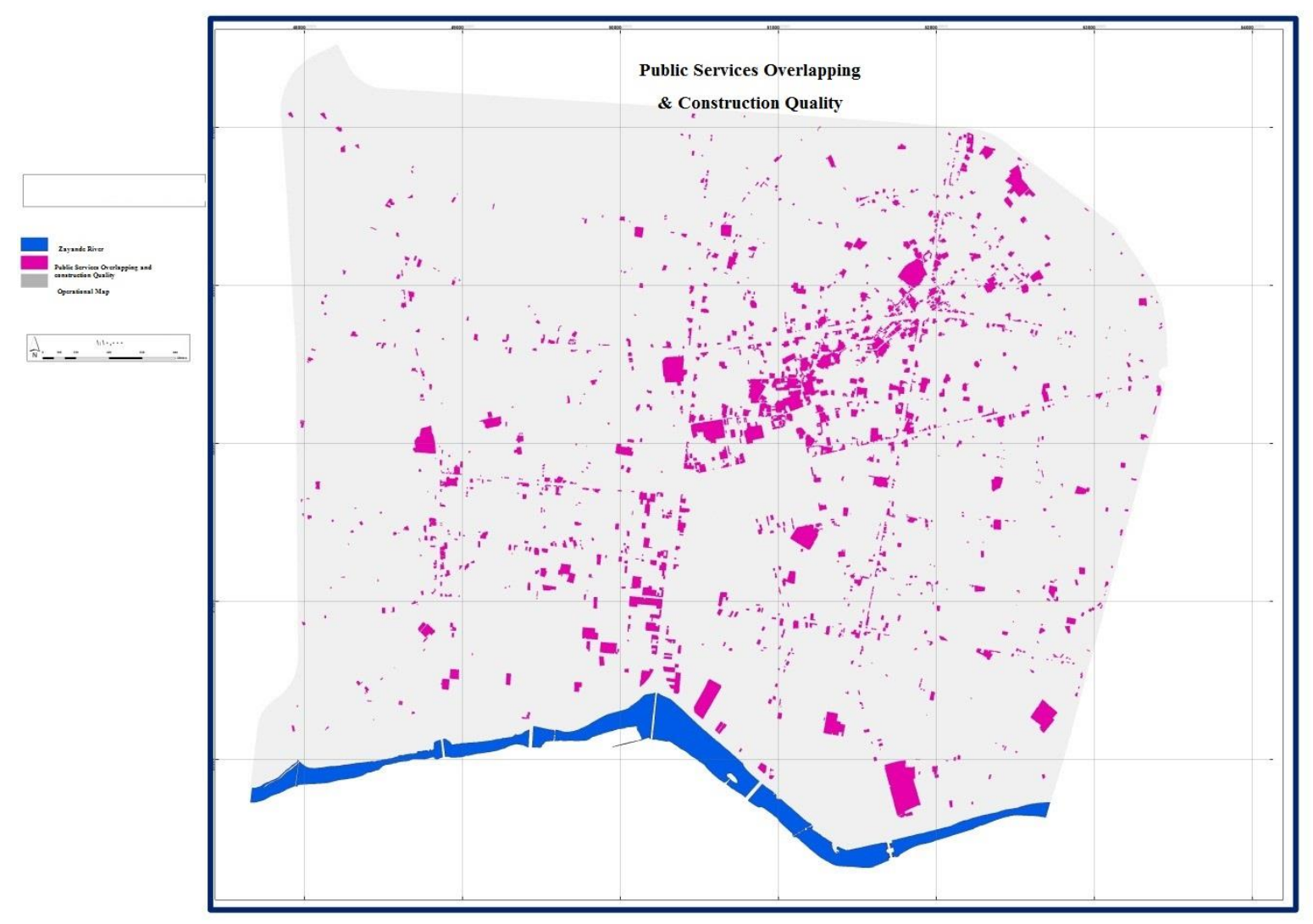

Figure 6. Final overlapping, regeneration strategies principles

Figure 6 illustrates the service structure layers overlapping and building quality. This overlapping was obtained from the corresponding adjacency and overlapping of the data layers from the indicators of these two fields. Finally, in Figure 7, the three data fields overlapping of sustainable physical regeneration are displayed. The strategic areas based on physical regeneration principles are specified by color on the map.

Analyzing the strategic areas based on the final overlapping map revealed that the north western district illustrated in Figure 8 cannot be a part of the physical regeneration scope of the study even though it has brownfields potential since it is detached from service structure, ecologic and open urban areas. In order to utilize the capacities of such areas, measures should be taken to improve the texture through organizing the open urban areas and provision of service structure. 


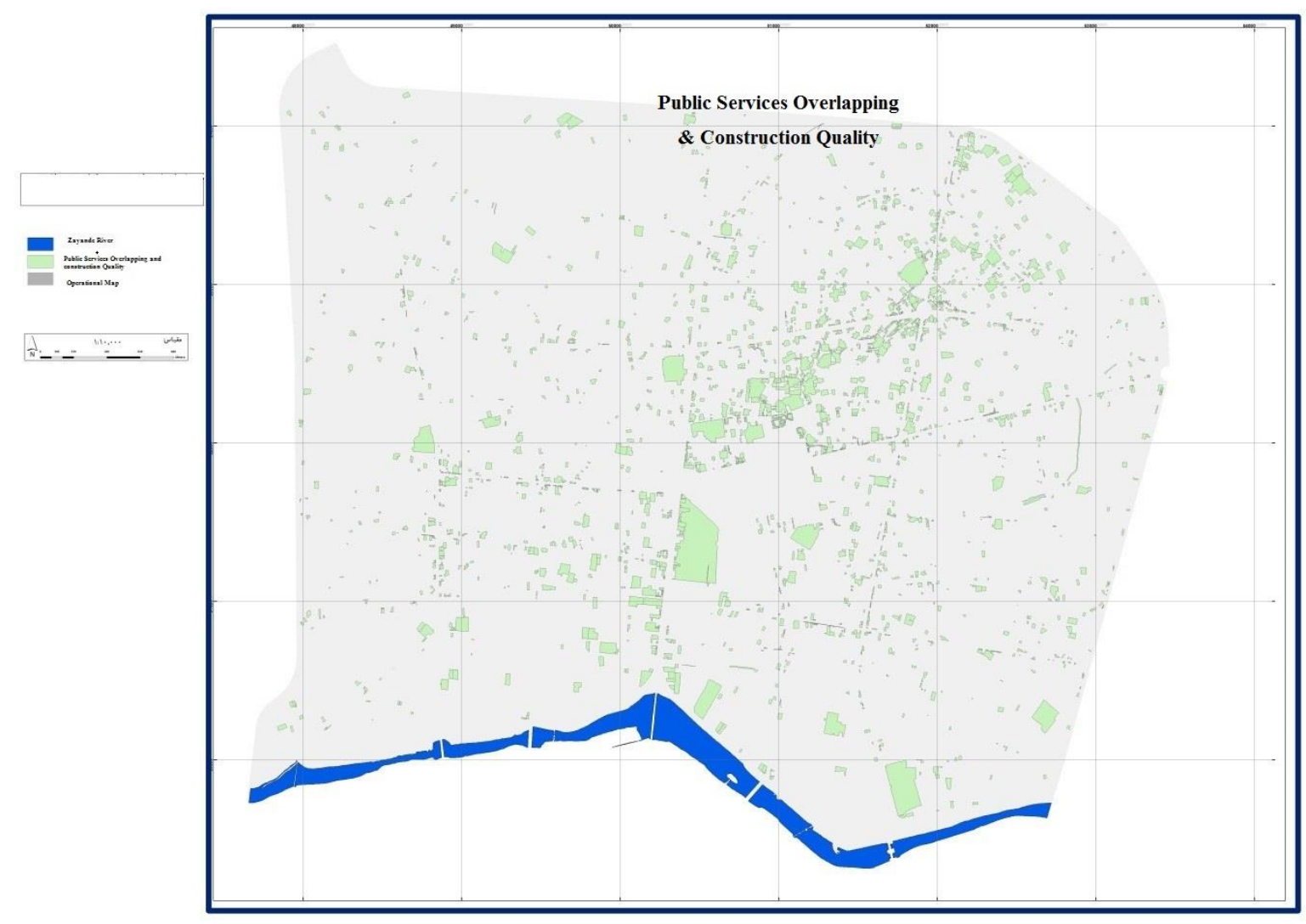

Figure 7. Final overlapping, strategic areas for restructuring

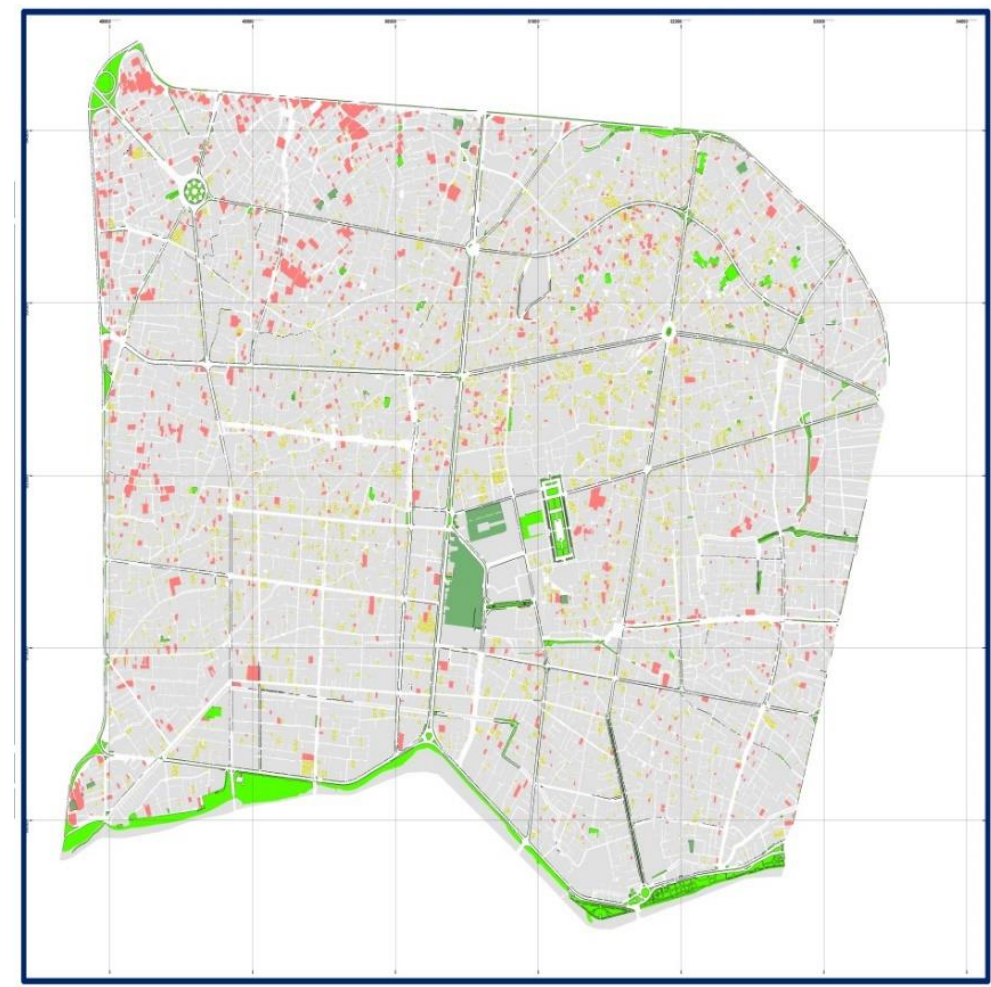

Figure 8. North Western District improvement capacity 


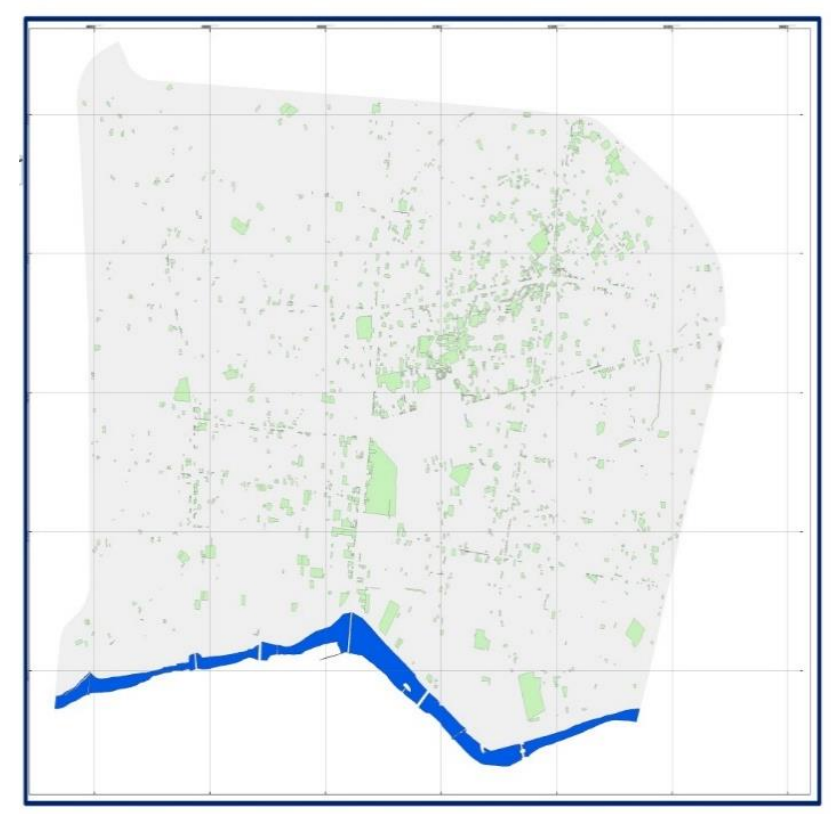

Figure 9. Structural gap

The structural gap in the final overlapping map and the inner development capacity of the North Western District are briefly compared in Figures 8 and 9. In order to remove this structural gap in restructurable areas of districts 1 and 3 of Isfahan, suggestions are proposed in the strategies section as follows.

\subsubsection{Adapting Final Overlapping Areas to Isfahan Historic Texture}

After extracting the final overlapping layers of sustainable urban regeneration together with the structural gap of the historic texture, the results and findings of the comparisons and analysis are presented in this section of the study. As shown in Figure 10, overlapping the zone-based historic-cultural layers of Isfahan with the final overlapping layer of sustainable urban regeneration strategies area, it was revealed that they were perfectly consistently matched. This shows that sustainable urban regeneration approach and physical regeneration interventions have many limitations. Since the main purpose of infill development is to make use of all inner site potentials and applying them to all inner areas, this is in relative opposition to the rules and regulations related to preserving the historic texture of this area. This reduces the physical interventions to preservation-oriented interventions. The best suggestion in these conditions is the activities function analysis based on sustainable urban regeneration. These functional interventions have the priority over other interventions. The only challenging problem this in districts 1 and 3. 
As mentioned before, the north-western districts have infill development potential such as brownfields and have a structural gap with the strategic areas of the district. Consequently, the substitute strategy that can get the area closer to sustainable urban regeneration is to apply physical interventions in the northwestern areas with brownfields. This approach both preserves the old historic texture and improves the district based on sustainable urban regeneration approach. The strategies taken to measure the development of Isfahan historic texture based on sustainable urban regeneration is presented as follow.

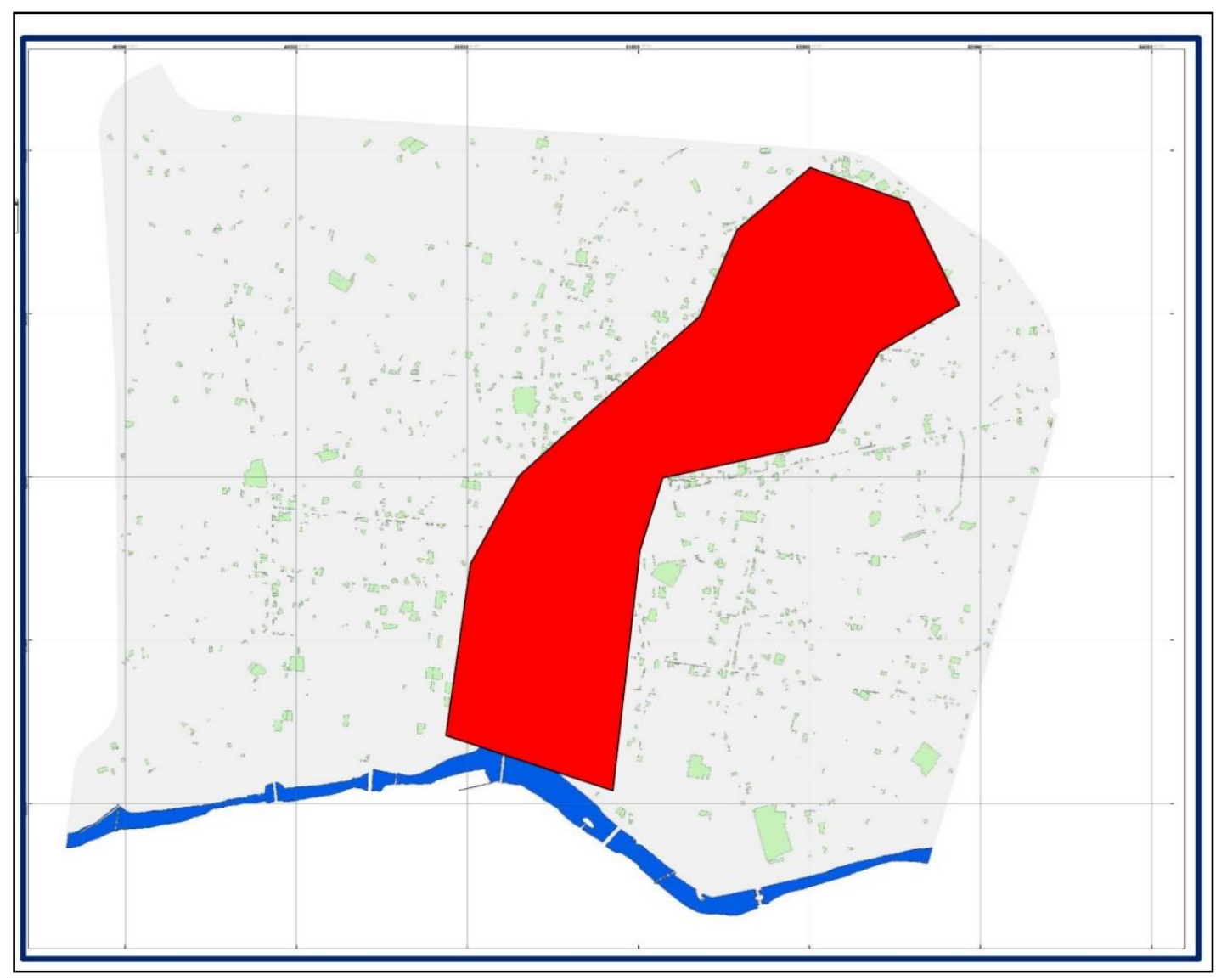

Figure 10. Adapting Isfahan cultural historic texture to strategic areas 


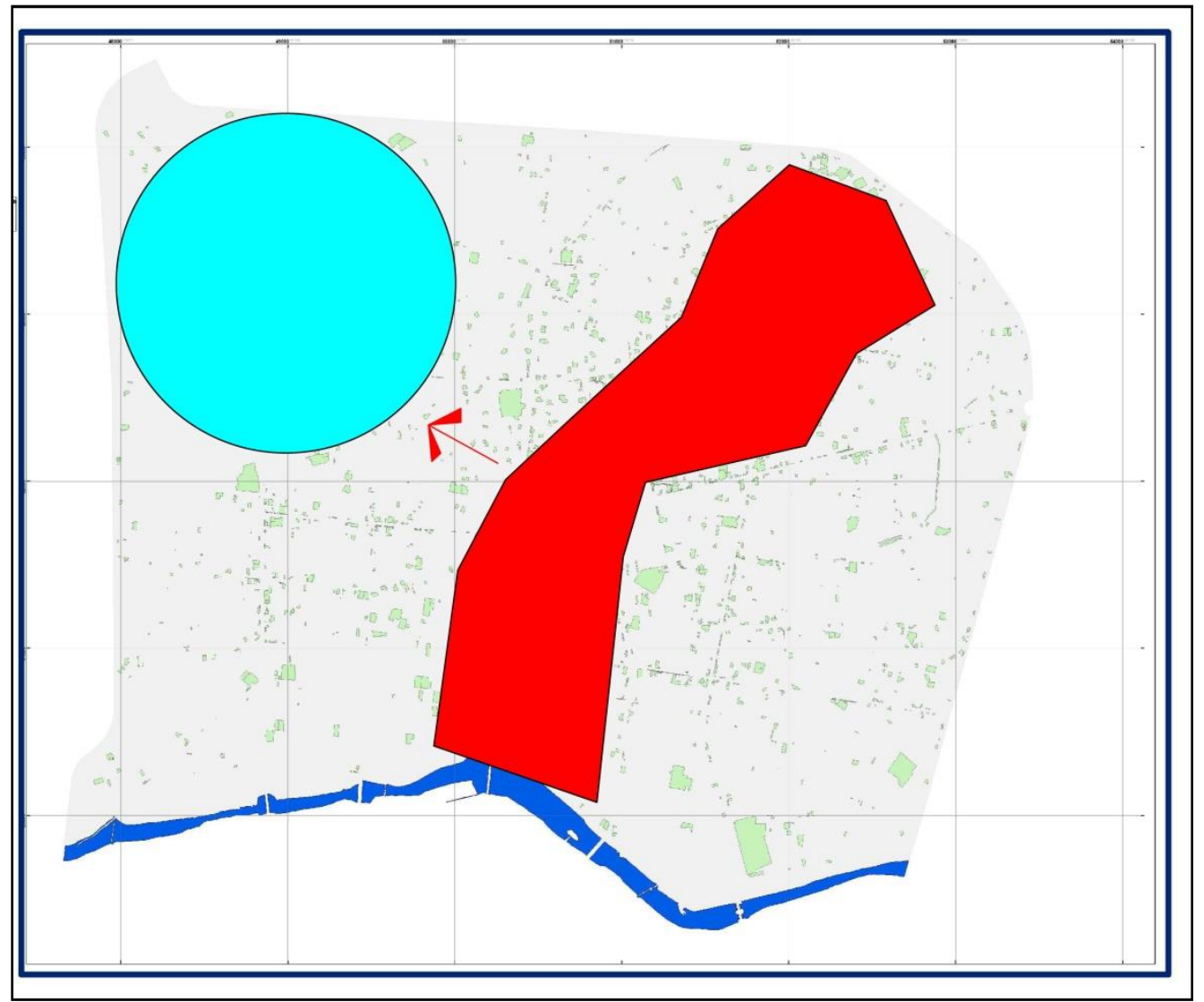

Figure 11. Substitute strategy, development and interventions in the northeastern districts

\section{Study Suggestions and Strategies}

Findings of the study considering the structural gap is divided into two main categories as follows:

$\bullet$

including residence, retail shops, ...

$\bullet$

spatial patterns in the area

use for concordant with social and physical texture

$\bullet$

design principles to preserve ecological areas

based on public transportation
Increased mixed-use

Paying attention to

Selecting appropriate

Observing urban

Utilizing development 
principles to preserve land value

$\bullet$

service structure according to historic urban needs

joint parkings

Substitute strategies and suggestions for Isfahan historic texture:

$\bullet$

activities in public services

-

brownfields

$\bullet$

areas complying with Isfahan natural structure

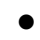

quality to improve urban space public services

$\bullet$

transportation in relation to service structure

$\bullet$

support in distressed areas

patterns in line with historic evolutionary trends
Outline zoning

Strengthening public

Encouraging to use
Using relevant

Optimum use of

Connecting to ecologic

Improving urban space

Improving public

Offering construction

Defining development 


\section{Resources}

Daneshvar, Abdi, Zohre (2004). An Introduction to Fundamental Theories of Planning with An Emphasis on Urban Planning. Ziba Arts Quartely. Number 15. pp. $42-57$

Falamaki, Mohammad Mansour (1979). An Analysis of Urban Regeneration Experiments in Iran. From Venice to Shiraz. Tehran: Ministry of Construction and Housing.

Galdini, Rossana (2005). Urban Regeneration Process: The Case of Genova. An Example of Integrated Urban Development Approach. Genova Development of Sociology and Social Sience.

Habibi, Seyyed Mohsen, Maghsoudi, Maliheh (2008). Urban Regeneration. Tehran: Tehran University.

Hajipour, Khalil (2007). An Introduction to Urban Regeneration Evolution Processes: From the First World War until the Third Millenium. Andishe IranShahr Quarterly. Second Year. Volume 9-10.

Hall, Peter (1997). Regeneration Policies for Peripheral Housing State: Inward and Outward Looking Approach. Urban Studies. 34, 873.

Hanachi, Pirooz, Khademzadeh, Muhammad Hussein, Shayan, Hamidreza, Kamelnia, Hamed, Mehdinezhad, Javad (2008). A Comparative Analysis of Urban Regeneration Experiments in Iran. Tehran: Sobhan Noor.

Iran Society of Condultant Engineers (2009). Planning and Urban Design Standards. Space and Space Making Volume. Translation Team: Giti Etemad, Mostafa Behzadfar, Sasan Salehi Milani, Tehran: Iran Society of Condultant Engineers.

Kalantary, Khalilabad, Hossein and Poorahmad, Ahmad (2007). Techniques and Experiences of Restoration of Urban Historical Texture. Tehran: Publication of Human Sciences Researches. Cultural and Social Studies of Jahad Daneshgahi. Second Publish.

Kamrava, Muhammad Ali (2011). Phenomenology of Distress Texture. Abstracts of Articles of the National Conference Rehabilitation and Recreation of Historical Texture. Distress Texture and Illegal Settlements of Shiraz.

Porats, N. (2004). Regeneration and Urban Projects, in Cities. Alinea Electric. Genova. Rogres, Richard (1999). Toward an Urban Renaissance. London: E and FN Spon.

Sahi Zadeh, Mahshid, Izadi, Mohammad Saeed (2008). Security and Urban Development. Two Complementary or Paradoxical Approaches, Number 45. 